\title{
Evidence of progressive deterioration of renal function in rats exposed to a maternal low-protein diet in utero
}

\author{
Margaret O. Nwagwu ${ }^{1}$, Anna Cook ${ }^{1}$ and Simon C. Langley-Evans ${ }^{2 *}$ \\ ${ }^{1}$ Department of University Medicine, Southampton General Hospital, Tremona Road, Southampton SO16 6YD, UK \\ ${ }^{2}$ University College Northampton, Boughton Green Road, Northampton NN2 7AL, UK
}

(Received 15 February 1999 - Revised 21 May 1999 - Accepted 23 July 1999)

\begin{abstract}
Intrauterine growth retardation associated with maternal undernutrition is proposed to play a significant role in the aetiology of hypertension and CHD. Animal experiments suggest that the kidney, which is extremely vulnerable to the adverse effects of growth-retarding factors, may play an important role in the prenatal programming of hypertension. Maintenance of renal haemodynamic functions following structural impairment in fetal life is proposed to require adaptations which raise systemic blood pressure and promote a more rapid progression to renal failure. Rats were fed on diets containing $180 \mathrm{~g}$ casein $/ \mathrm{kg}$ (control) or $90 \mathrm{~g}$ casein $/ \mathrm{kg}$ (low protein) during pregnancy. The offspring were studied in terms of blood pressure, creatinine clearance, blood urea N, plasma and urinary albumin, renal morphometry and metabolic activity at 4, 12 and 20 weeks of age. Blood pressure was elevated at all ages in the low-protein-exposed offspring, relative to control rats. Rats (4 weeks old) exposed to the low-protein diet had smaller kidneys which were shorter and wider than those of control animals. Creatinine clearance was significantly reduced in 4-week-old rats exposed to the low-protein diet. Renal morphometry and creatinine clearance at older ages were not influenced by prenatal diet. Blood urea $\mathrm{N}$, urinary output and urinary albumin excretion were, however, significantly greater in low-protein-exposed rats than in control rats at 20 weeks of age. These findings are suggestive of a progressive deterioration of renal function in hypertensive rats exposed to mild maternal protein restriction during fetal life. This is consistent with the hypothesis that adaptations to maintain renal haemodynamic functions following impairment of fetal nephrogenesis result in an accelerated progression towards glomerulosclerosis and increased intrarenal pressures mediated by rising vascular resistance.
\end{abstract}

\section{Kidney: Hypertension: Low-protein diets: Maternal nutrition}

Patterns of intrauterine growth retardation induced by fetal exposure to maternal undernutrition have been associated with cardiovascular disease and diabetes in a number of epidemiological studies (Barker, 1994). These findings have been confirmed by animal studies, particularly those in which rats are exposed to protein restriction in utero (Langley-Evans, 1998). Animal experiments have revealed a number of possible mechanisms by which cardiovascular disease might be programmed and the kidney has emerged as a key organ in the programming process (Langley-Evans, 1998).

The fetal kidney is extremely vulnerable to the effects of growth retardation and has been shown to be disproportionately affected in growth-retarded human infants (Hinchcliffe et al. 1992; Konje et al. 1996). In particular, in both rats and human subjects, the numbers of nephrons within the kidneys are reduced by growth-retarding stimuli, including maternal low-protein diets (Zeman, 1968; Gilbert et al. 1991; Hinchcliffe et al. 1992; Merlet-Benichou et al.
1994; Celsi et al. 1997; Langley-Evans et al. 1999b). It is proposed that adaptations to preserve the haemodynamic functions of the kidneys in postnatal life result in both hypertension and an accelerated progression towards glomerulosclerosis and renal failure (Mackenzie \& Brenner, 1995).

Previous work with rats in our laboratory has demonstrated severe impairment of late gestation nephrogenesis by exposure to low-protein diets, but with no haemodynamic functional deficit at 20 weeks postnatal age (Langley-Evans et al. 1999b). We hypothesize that whilst glomerular filtration may be maintained through rising renal vascular resistance and blood pressure, this adaptation will be associated with a progressive deterioration of the glomeruli and changes in glomerular permeability and protein excretion. With evidence of a renal structural impairment (LangleyEvans et al. 1999b), it is now important to consider the functional impact of such an impairment. In the present 
paper this is assessed in rats exposed to low-protein diets in utero, at 4, 12 and 20 weeks of age.

\section{Materials and methods \\ Chemicals and reagents}

Unless stated otherwise in the text all chemicals and reagents were of analytical grade and purchased from Sigma UK (Poole, Dorset, UK).

\section{Animals}

All of the animal experimentation detailed in this work was performed under licence from the Home Office. Mature Wistar rats were purchased from Harlan UK (Belton, Leics., UK) and on arrival in the Southampton University Animal Facility were allowed 2 weeks to acclimatize before the experiments commenced. Pregnant rats were housed in plastic boxes in pairs until the last $2 \mathrm{~d}$ of pregnancy, when individual housing was imposed. The weaned offspring of the pregnant rats were housed in groups of four. All rats were given free access to food and water and were kept in a room maintained at $22^{\circ}$ with a $12 \mathrm{~h}$ light cycle.

\section{Protocol}

Sixteen virgin female Wistar rats were used in the experiment to generate a total of 150 offspring. Rats were mated at a weight of $200-225 \mathrm{~g}$ by housing with stock males. On confirmation of pregnancy, by the observation of a semen plug on the floor of the mating cage, rats were allocated to receive either a control diet $(180 \mathrm{~g}$ casein $/ \mathrm{kg})$, or a lowprotein diet $(90 \mathrm{~g}$ casein $/ \mathrm{kg})$. The control and low-protein diets were balanced in terms of energy $(28 \mathrm{MJ} / \mathrm{kg} \mathrm{diet})$, fat, fibre and micronutrient content. The composition of each diet is presented elsewhere (Langley-Evans et al. 1996b). Feeding of the diets continued until the rats delivered, at which point all rats were provided with a standard laboratory chow diet (CRME, Special Diet Services Ltd, Witham, Essex, UK). At birth, the weights of all pups were recorded and the litters were culled to a maximum of eight animals (Langley-Evans et al. 1996b). One rat fed on the lowprotein diet failed to deliver.

The offspring were weaned onto CRME diet at 4 weeks of age. At this time, the blood pressures of all animals were recorded and half the rats in each litter were housed for $24 \mathrm{~h}$ in metabolic cages for the collection of urine. Urine volume was determined gravimetrically and then stored at $-80^{\circ}$. These 4-week-old rats were then killed by overdose with sodium pentobarbital. Blood was collected by cardiac puncture, transferred to heparinized tubes and centrifuged at $3000 \mathrm{rev} . / \mathrm{min}$ for $10 \mathrm{~min}$ at $4^{\circ}$. Plasma was stored at $-80^{\circ}$. Hearts, brains, lungs, livers and spleens were rapidly excised and snap-frozen in liquid $\mathrm{N}_{2}$. Tissues were stored at $-80^{\circ}$ for up to 3 months before biochemical analyses. Remaining animals had blood pressure assessed and urine collected at 12 or 20 weeks and were then killed for tissue collection, as at 4 weeks of age. Fewer animals were culled at 12 weeks than at 20 weeks, to enhance the number of samples available from mature rats. Such animals would be more likely to exhibit renal functional deficits.

\section{Determination of blood pressure}

Systolic blood pressure and heart rate were determined using an indirect tail-cuff method, as previously described in detail (Sherman \& Langley-Evans, 1998).

\section{Renal morphometry}

On killing the kidneys were rapidly excised and weighed. The left kidney was snap-frozen in liquid $\mathrm{N}_{2}$ and stored at $-80^{\circ}$ for up to 6 months before biochemical analysis. The right kidney was carefully weighed and its length measured using calipers to within $0.5 \mathrm{~mm}$ accuracy, and other measurements were made of width in the lateral and transverse planes through the hilar region. To provide estimates of renal size and shape, renal weight was expressed as a proportion of body weight and kidney length as a function of renal weight. The lateral and transverse width measurements were expressed in relation to renal length.

\section{Determination of albumin, creatinine and blood urea nitrogen}

Plasma and urinary albumin concentrations were determined using the bromocresol green method, as reported previously (Langley et al. 1994b). Urinary albumin concentrations were expressed per mg creatinine to control for major variations in urinary volume observed in the two groups of animals. Creatinine was also determined in plasma to permit estimation of creatinine clearance as a crude index of glomerular filtration rate. Creatinine was estimated using the alkaline picrate method (Bowers \& Wong, 1980). Blood urea $\mathrm{N}$ (BUN) provides an index of the relative production of urea by the liver and its elimination by the kidneys (Owen et al. 1993). BUN was determined in plasma samples using a commercially available kit (Sigma).

\section{Determination of renal enzyme activities}

Alkaline phosphatase (EC 3.1.3.1; ALP) and angiotensin converting enzyme (EC 3.4.15.1; ACE) were assayed in kidney, as indices of general metabolic activity and reninangiotensin system activity respectively. Frozen kidneys were homogenized in $20 \mathrm{mM}$-potassium phosphate buffer, $\mathrm{pH} 8 \cdot 3$, to give a tissue concentration of $100 \mathrm{mg} / \mathrm{ml}$. Homogenates were centrifuged at $4000 \mathrm{~g}$ for $10 \mathrm{~min}$ at $4^{\circ}$ and the supernatant fraction was retained as two separate aliquots. ALP activity was determined in the supernatant fraction utilizing an ALP kit (Sigma). ACE activity was determined using hippuryl-histidinyl-leucine as the substrate, as previously reported by Langley \& Jackson (1994). Both enzyme activities were expressed per mg protein. The protein content of the kidney supernatant fraction was determined using the bicinchoninic acid method of Smith et al. (1985).

\section{Statistical analysis}

All data are presented as means with their standard errors (SEM). Data were analysed using one- or two-way ANOVA, 
with a Tukey test post hoc or Students $t$ test as appropriate. A probability of $5 \%$ or less was accepted as statistically significant.

\section{Results}

At birth the weights of offspring from the two dietary groups were similar (control $n$ 89: 5.52 (SE 0.07) g, low protein $n$ 61: 5.50 (SE 0.09) g). Litter size was similarly unaffected by maternal protein restriction (control $n$ 8: 11 (SE 1) pups/ litter, low protein $n$ 7: 9 (SE 1) pups/litter). Systolic blood pressure and heart rate were measured in all animals at 4,12 and 20 weeks of age (Table 1). Blood pressure was significantly elevated in the low-protein-exposed group, relative to the control group, at all ages studied. The magnitude of the pressure difference increased from $7 \mathrm{mmHg}$ to $21 \mathrm{mmHg}$ between 4 and 20 weeks. Low-protein-exposed rats had significantly lower heart rates at 4 and 12 weeks of age, but heart rates were similar in the two groups at 20 weeks.

Table 2 shows relative renal size and shape at 4,12 and 20 weeks. Whilst male ( $n 16,10$ respectively for control and low-protein groups at 4 weeks, $n 7,4$ at 12 weeks and $n 8,5$ at 20 weeks) and female ( $n$ 16, 12 respectively for control and low-protein groups at 4 weeks, $n$ 4, 3 at 12 weeks, and $n 9,11$ at 20 weeks) rats differed in terms of body weight, and hence kidney weight, no sex-related differences in renal size as a percentage of body weight or the ratios renal length: renal weight, or renal width : length were observed. Thus, the data are shown for males and females combined. Overall renal size was significantly smaller in 4-week-old animals exposed to a low-protein diet in utero, compared with control animals. These smaller kidneys were short in proportion to their weight, but were wider in the transverse plane than control kidneys. In effect the young low-proteinexposed rats had shorter, fatter kidneys than control animals. At 12 weeks of age no differences in renal morphometry were noted between the two groups, whilst at 20 weeks the low-protein exposed rats had thinner kidneys than control rats, when measured in the transverse plane.

Measurements of plasma albumin and BUN (Table 1), indicated that the metabolism and clearance of protein in the low-protein-exposed animals, differed from that of control rats. Plasma albumin concentrations were greater in 12week-old animals than in 4- or 20-week-old rats $(P<$ $0 \cdot 001$ ), but were unaffected by maternal dietary factors. BUN concentrations increased markedly between 4 and 12 weeks of age $(P<0 \cdot 001)$. In 20 -week-old animals, but not younger animals, fetal exposure to a maternal low protein diet resulted in higher BUN concentrations than observed in control rats.

The urine outputs of control and low-protein-exposed animals were similar at 4 weeks of age (Table 1). At 12 weeks and 20 weeks the urine volume collected over $24 \mathrm{~h}$ was significantly greater in the low protein exposed group than in controls (approximately $70 \%$ greater). Excretion of albumin in the urine (corrected for urinary creatinine concentration) was significantly greater (2-fold) in the 20week-old low-protein-exposed rats than in control rats. The level of albumin in the urine of the older low-proteinexposed rats was, however, similar to the level noted in

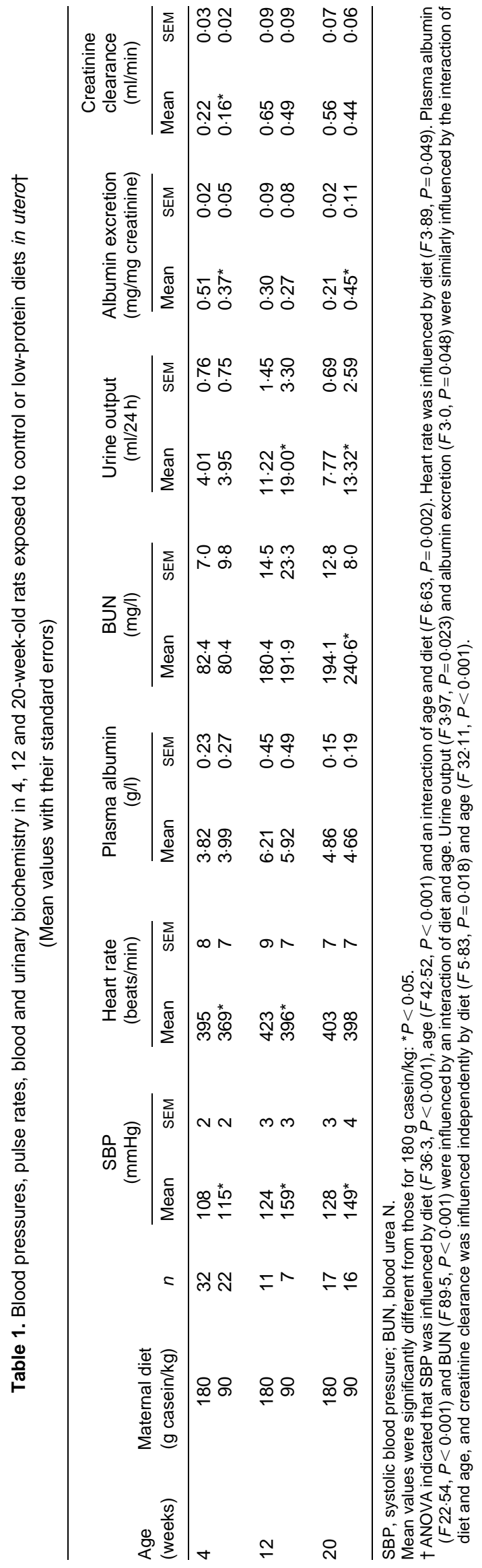


Table 2. Renal morphometry at 4, 12 and 20 weeks of age in rats exposed to control or low-protein diets in utero† (Mean values with their standard errors)

\begin{tabular}{|c|c|c|c|c|c|c|c|c|c|c|}
\hline \multirow{2}{*}{$\begin{array}{l}\text { Age } \\
\text { (weeks) }\end{array}$} & \multirow{2}{*}{$\begin{array}{l}\text { Maternal diet } \\
\text { (g casein } / \mathrm{kg} \text { ) }\end{array}$} & \multirow[b]{2}{*}{$n$} & \multicolumn{2}{|c|}{$\begin{array}{c}\text { Kidney weight : body } \\
\text { weight } \\
(\%)\end{array}$} & \multicolumn{2}{|c|}{$\begin{array}{l}\text { Kidney } \\
\text { length: kidney } \\
\text { weight }(\mathrm{mm} / \mathrm{g})\end{array}$} & \multicolumn{2}{|c|}{$\begin{array}{l}\text { Lateral : length } \\
\quad \text { ratio }\end{array}$} & \multicolumn{2}{|c|}{$\begin{array}{l}\text { Transverse: length } \\
\text { ratio }\end{array}$} \\
\hline & & & Mean & SEM & Mean & SEM & Mean & SEM & Mean & SEM \\
\hline 4 & $\begin{array}{r}180 \\
90\end{array}$ & $\begin{array}{l}32 \\
22\end{array}$ & $\begin{array}{l}0.53 \\
0.51^{\star}\end{array}$ & $\begin{array}{l}0.01 \\
0.01\end{array}$ & $\begin{array}{l}34.9 \\
31 \cdot 7^{*}\end{array}$ & $\begin{array}{l}1.4 \\
1.0\end{array}$ & $\begin{array}{l}0.50 \\
0.46\end{array}$ & $\begin{array}{l}0.02 \\
0.02\end{array}$ & $\begin{array}{l}0.55 \\
0.60^{\star}\end{array}$ & $\begin{array}{l}0.02 \\
0.02\end{array}$ \\
\hline 12 & $\begin{array}{r}180 \\
90\end{array}$ & $\begin{array}{r}11 \\
7\end{array}$ & $\begin{array}{l}0.39 \\
0.40\end{array}$ & $\begin{array}{l}0.01 \\
0.03\end{array}$ & $\begin{array}{l}15 \cdot 0 \\
14 \cdot 4\end{array}$ & $\begin{array}{l}0.8 \\
0.8\end{array}$ & $\begin{array}{l}0.44 \\
0.41\end{array}$ & $\begin{array}{l}0.01 \\
0.01\end{array}$ & $\begin{array}{l}0.58 \\
0.58\end{array}$ & $\begin{array}{l}0.01 \\
0.02\end{array}$ \\
\hline 20 & $\begin{array}{r}180 \\
90\end{array}$ & $\begin{array}{l}17 \\
16\end{array}$ & $\begin{array}{l}0.32 \\
0.34\end{array}$ & $\begin{array}{l}0.01 \\
0.01\end{array}$ & $\begin{array}{l}17 \cdot 3 \\
17 \cdot 9\end{array}$ & $\begin{array}{l}1 \cdot 1 \\
0.5\end{array}$ & $\begin{array}{l}0.46 \\
0.44\end{array}$ & $\begin{array}{l}0.02 \\
0.01\end{array}$ & $\begin{array}{l}0.62 \\
0.57^{\star}\end{array}$ & $\begin{array}{l}0.02 \\
0.02\end{array}$ \\
\hline
\end{tabular}

Mean values were significantly different from those for $180 \mathrm{~g}$ casein $/ \mathrm{kg}$ diet: ${ }^{\star} P<0.05$.

$\dagger$ ANOVA indicated that the interaction of diet and age influenced kidney weight : body weight $(F 21.54, P<0.001)$, kidney length : kidney weight $(F 6.60, P=0.002)$ and transverse width : kidney length $(F 2 \cdot 76, P=0.025)$. The lateral width : length value was influenced by age alone $(F 4.18, P=0.018)$.
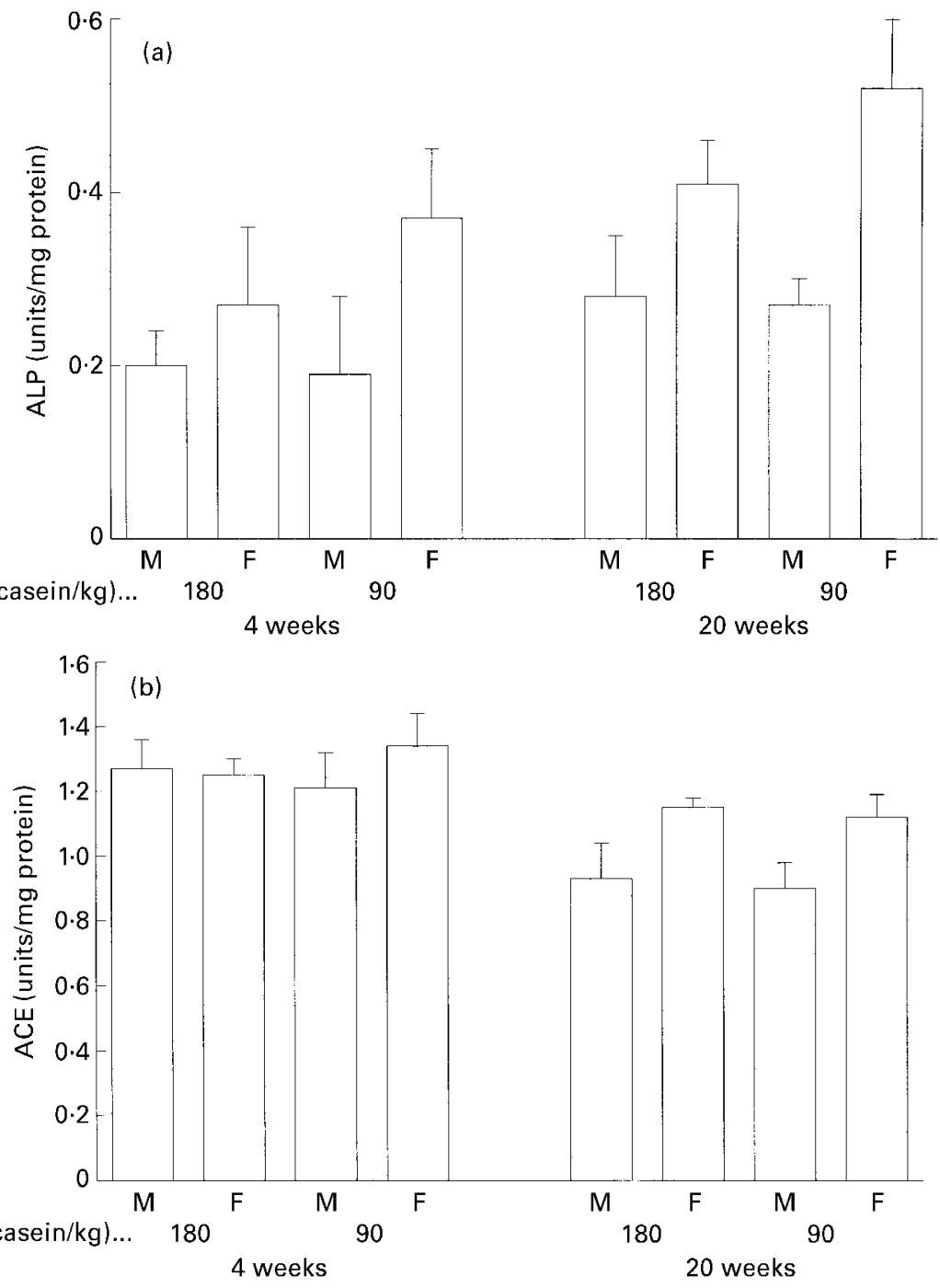

Fig. 1. (a) Renal alkaline phosphatase (ALP) activity and (b) renal angiotensin converting enzyme (ACE) activity in male (M) and female (F) offspring (at 4 and 20 weeks of age) of rats fed on diets containing 180 or $90 \mathrm{~g}$ casein/kg during gestation. Values are means with their standard errors represented by vertical bars. Numbers of animals in each group were; control: 4 weeks old, male $n 16$, female $n 16,20$ weeks old, male $n 8$, female $n 8$; low-protein: 4 weeks old, male $n 10$, female $n 12,20$ weeks old, male $n 5$, female $n 11$. Units of ALP activity are $\mu$ mol p-nitrophenol produced/min per mg protein; units of ACE activity are $\mu \mathrm{mol}$ hippuryl-histidinyl-leucine hydrolysed/min per mg protein. ANOVA indicated a significant effect of sex on ALP activity $(F 6.3, P=$ $0.014)$ and an effect of age on ACE activity $(F 4.585, P=0.013)$. No higher order interactions were observed. 
4-week-old control rats. Creatinine clearance, a marker of glomerular filtration rate, increased between 4 and 12 weeks of age $(P<0.001)$. Four-week-old animals exposed to the low-protein diet had significantly lower creatinine clearance than control animals and tended to have lower clearance rates at 12 and 20 weeks, although these latter trends failed to achieve statistical significance. Two-way ANOVA indicated independent effects of diet $(P=0.018)$ and age $(P<$ 0.001) on creatinine clearance.

Renal activities of the enzymes ALP and ACE differed between males and females and thus the results for the two sexes were analysed separately (Fig. 1). ALP activity was unaffected by age or maternal dietary protein restriction in both males and females. Whilst ACE activity was significantly lower in the kidneys of 20-week-old rats than 4week-old rats $(P=0.02)$, the activities of control and lowprotein exposed rats were similar.

\section{Discussion}

The aim of the current investigation was to examine the impact of fetal exposure to maternal protein restriction on the long-term renal function of young and adult rats. Previous studies have demonstrated that the rat kidney is particularly sensitive to intrauterine protein restriction. Severe restriction of protein to 50 or $60 \mathrm{~g} / \mathrm{kg}$ in the maternal diet impairs the development of the kidney and results in reduced nephron number (Zeman, 1968; Merlet-Benichou et al. 1994). The level of protein supplied by the $90 \mathrm{~g}$ casein/ $\mathrm{kg}$ diet, in the present study, represents a relatively mild nutrient restriction (Langley-Evans, 1998). This manipulation of the maternal diet has previously been shown to impair late gestation nephrogenesis, produce kidneys with a reduced nephron complement and to induce hypertension in the offspring (Langley-Evans et al. 1999b). The data presented in the present paper demonstrate, consistent with the previous findings, that the renal function of adult rats exposed to a low-protein diet in utero, is compromised by their fetal environment.

The feeding of a $90 \mathrm{~g}$ casein $/ \mathrm{kg}$ diet in rat pregnancy is known to have no appreciable effect on maternal food intake and to slightly reduce weight gain in late pregnancy (Langley-Evans et al. 1996c). The outcome of pregnancy is not adversely affected (Langley-Evans et al. 1994), as evidenced by the fact that litter sizes did not differ significantly between the two dietary groups. Birth weight was found to be unaltered by maternal protein restriction. Our previous studies have shown that offspring of rats fed on the lowprotein diet are of low-to-normal birth weight, but more importantly exhibit evidence of disproportion at birth (Langley-Evans et al. 1996a), a known risk factor for hypertension and diabetes in the human population (Barker, 1994). Rat pups exposed to the low-protein diet in fetal life, undergo late gestation retardation of truncal growth, whilst brain growth is relatively spared. The impact of truncal growth retardation on the kidneys appears to be severe, with a marked reduction in the number of new nephrons formed in the last $2 \mathrm{~d}$ of gestation and in the postnatal period (Langley-Evans et al. 1999b). The finding of elevated blood pressure and lower heart rates in rats exposed to maternal low-protein diets was consistent with numerous previous reports from our laboratory (LangleyEvans et al. 1996a,b,c; Sherman \& Langley-Evans, 1998).

Simple measures of renal morphometry were made at 4 , 12 and 20 weeks of age to complement a previous determination of reduced nephron number in low-protein-exposed rats (Langley-Evans et al. 1999b). This was of interest as Konje et al. (1996) demonstrated, in an ultrasound study of human fetal growth, that small-for-dates fetuses had kidneys which were longer and thinner than those in appropriate-fordates fetuses. In the present study we found no evidence of this 'sausage-shaped' kidney, as it has been termed. At 4 weeks old, rats exposed to the low-protein diet in utero had smaller kidneys as a proportion of body weight than control animals and these kidneys were shorter, but broader in the transverse plane than those of control rats. Although different in shape from that proposed by Konje et al. (1996), these kidneys do suggest that the gross morphology of the organ may be susceptible to fetal remodelling by the maternal diet. In older rats the size and shape of the kidneys were largely unchanged. Increases in size and proportions may result from accumulation of water or other age-related changes to the tissue structure. Furthermore the lower sample sizes, particularly at 12 weeks of age, may make interpretation of gross morphology in older animals unreliable. Two-way ANOVA suggested that there were agerelated effects of diet on renal size in proportion to body weight $(P<0.001)$, kidney length as a proportion of organ weight $(P<0.001)$ and transverse dimension in relation to kidney length $(P<0.05)$.

Biochemical measures of blood composition and urinary indicators of renal status indicated several differences between rats exposed to control and low-protein diets during fetal life. Plasma albumin concentrations were similar in the two groups, indicating normal hepatic metabolism in the low-protein-exposed group. This is consistent with the findings of Langley et al. (1994b). BUN increased in both dietary groups with age. BUN is a marker of the balance between hepatic urea production and renal excretion (Owen et al. 1993). A raised BUN level is reflective of either hepatic or renal dysfunction and is observed in renal failure, severe congestive heart failure, dehydration and states of raised protein catabolism (Owen et al. 1993). The observation of rising BUN concentration with age, alongside normal plasma albumin, seen in this study, is indicative of progressive deterioration of renal function in all of the ageing rats. BUN concentrations were significantly greater in the low-protein-exposed group at 20 weeks of age than in controls. This suggests an accelerated deterioration of renal function in these hypertensive animals. Moreover BUN correlated significantly with systolic blood pressure at both 4 and 20 weeks of age (overall $r 0.361, P=0.04$ ).

The indication from the BUN results that renal function may be impaired by intrauterine low-protein exposure, is consistent with urinary observations. At 12 and 20 weeks of age, low-protein-exposed animals produced significantly more urine than the control animals and had higher urinary albumin: creatinine values. This is suggestive of microalbuminuria and a reduction of the permeability of the glomerular membranes. Urine volume was strongly correlated with blood pressure $(r 0.518, P<0.001)$. A simple interpretation of the increase in urine volume is that renal 
function is compromised. Urine volume may also be elevated by the need to balance circulating electrolytes or to excrete an excess of waste.

Creatinine clearance is another commonly used marker of renal haemodynamic functions and is a proxy for the glomerular filtration rate (GFR). In rats this may be measured as in the present study, by examining clearance in a $24 \mathrm{~h}$ urine sample. This is the method used in human investigations (Duarte \& Preuss, 1993). Invasive techniques are also used in animals, but these cannot be repeated in the same animals and are extremely time consuming, requiring cannulation of veins, arteries and urethra under anaesthesia (Langley-Evans et al. 1999b). Although the present technique does not represent the 'gold standard' for this measurement, it was adopted to allow investigation of greater numbers of animals than considered in our previous cannulation experiments (Langley-Evans et al. 1999b).

Creatinine clearance was significantly lower in 4-weekold rats exposed to low-protein diets in utero than in control animals, and tended (not significantly) to be lower at 12 and 20 weeks of age. The lack of significance in older rats may relate to the smaller sample size relative to 4 -week data. The magnitude of the difference between control and lowprotein-exposed rats was in fact similar at all ages and two-way ANOVA suggested separate effects of age $(P<$ $0.001)$ and maternal diet $(P<0.05)$ on creatinine clearance. This suggestion of impaired GFR in low-protein-exposed rats is not wholly inconsistent with earlier studies of 20week-old animals. Cannulation studies suggested normal GFR in older animals, but did not consider younger rats. The findings, as with those of Hall \& Zeman (1968), who studied neonates, suggest that impairment of GFR is more severe in the early postnatal period and that with ageing, physiological adaptations occur to preserve GFR and renal function. One such adaptation may be a progressive increase in blood pressure at the intrarenal and systemic level, through increased vascular resistance. This may be mediated by an increased activity of the renin-angiotensin system. Studies with the offspring of rats fed on low-protein diets in pregnancy support the hypothesis of increased vascular sensitivity to angiotensin II (Langley-Evans et al. 1999a).

The similar ALP and ACE activities of control and lowprotein-exposed rats indicate that maternal undernutrition does not alter the metabolic activity of the kidney. Interestingly ACE activity is known to be elevated in lung and plasma, and is believed to contribute to the raised blood pressure of low-protein-exposed rats (Langley-Evans et al. 1999a). The present finding suggests tissue-specific programming of ACE activity or expression.

The pattern of renal deterioration and especially the increase in urine output might alternatively be explained by the development of diabetes in the low-protein exposed rats. Several studies using a low-protein diet, of differing composition to that used here, have demonstrated intrauterine programming of pancreatic structure (Snoeck et al. 1990), islet function (Dahri et al. 1991) and defects of glucose and insulin metabolism (Ozanne et al. 1996). Insulin-dependent and non-insulin-dependent diabetes may generate elevated BUN levels by virtue of the dehydration state associated with the conditions (Luke, 1981). Insulindependent diabetes may also elevate urinary albumin concentration and a high proportion of diabetic patients develop nephropathy associated with protein loss. With the animal model studied in the present paper, however, there is no evidence of programmed diabetes, although 8-week-old rats exposed to the low-protein diet appear to clear an intravenous glucose load more rapidly than control animals (Langley et al. 1994a). At 16 weeks old, rats exhibited similar responses to glucose to those observed in control rats (Pickard et al. 1996). Since creatinine clearance was impaired at 4 weeks of age and urine volume increased by 12 weeks, it is unlikely that the observed deterioration of renal function represents a diabetic nephropathy, as opposed to being a consequence of renovascular changes.

Mackenzie \& Brenner (1995) proposed that programming of renal structure may underlie associations between maternal undernutrition and later hypertension. Impairment of nephrogenesis due to fetal nutrient restraint was envisaged as raising local and systemic blood pressures as a means of maintaining essential renal haemodynamic functions. Raised local pressures within the nephrons would be expected to accelerate the degradation of those nephrons and the progress of the animal towards glomerulosclerosis and renal failure. Our earlier studies have demonstrated that mild intrauterine protein restriction, which is associated with adult hypertension, impairs late gestation nephrogenesis and produces a structurally altered kidney (LangleyEvans et al. 1999b). The current work indicates that this structural alteration does appear to precipitate a more rapid decline of function, manifesting as elevated BUN, increased urine output and microalbuminuria. The observation of reduced creatinine clearance early in life suggests that adaptations to maintain GFR, which may include increases in blood pressure, may occur and contribute to renal deterioration, as hypothesized by Mackenzie \& Brenner (1995).

\section{Acknowledgements}

This work was supported by a grant from the Medical Research Council. Anna Cook was a visiting student from the Royal Melbourne Institute of Technology, Australia.

\section{References}

Barker DJP (1994) Mothers, Babies and Disease in Later Life. London: BMJ Publishing Group.

Bowers CD \& Wong ET (1980) Kinetic serum creatinine assays: a critical evaluation. Clinical Chemistry 26, 555-561.

Celsi G, Kistner A, Eklof A-C, Ceccatelli S, Aizman R \& Jacobson S (1997) Inhibition of renal growth by prenatal dexamethasone and the programming of blood pressure in the offspring. Journal of the American Society of Nephrology 8, A1360.

Dahri S, Snoeck A, Reusens-Billen B, Remacle C \& Hoet JJ (1991) Islet function in offspring of mothers on low-protein diet during gestation. Diabetes 40, Suppl. 2, 115-120.

Duarte CG \& Preuss HG (1993) Assessment of renal function: glomerular and tubular. Clinics in Laboratory Medicine 13, 33-52.

Gilbert T, Lelievre-Pegorier M \& Merlet-Benichou C (1991) Long term effects of mild oligonephronia induced in utero by gentamycin in the rat. Pediatric Research 30, 450-456.

Hall SM \& Zeman FJ (1968) Kidney function of the progeny of rats fed a low protein diet. Journal of Nutrition 95, 49-56.

Hinchcliffe SA, Lynch MRJ, Sargent PH, Howard CV \& van 
Zelzen D (1992) The effect of intrauterine growth retardation on the development of renal nephrons. British Journal of Obstetrics and Gynaecology 99, 296-301.

Konje JC, Bell SC, Morton JJ, De Chazal R \& Taylor DJ (1996) Human fetal kidney morphometry during gestation and the relationship between weight, kidney morphometry and plasma active renin concentration at birth. Clinical Science 91, 169-175.

Langley SC, Browne RF \& Jackson AA (1994a) Altered glucose tolerance in rats exposed to maternal low protein diets in utero. Comparative Biochemistry and Physiology 109A, 223-229.

Langley SC \& Jackson AA (1994) Increased systolic blood pressure in adult rats induced by fetal exposure to maternal low protein diet. Clinical Science 86, 217-222.

Langley SC, Seakins M, Grimble RF \& Jackson AA (1994b) The acute phase response of adult rats is altered by in utero exposure to maternal low protein diets. Journal of Nutrition 124, 1588-1596.

Langley-Evans SC (1998) Nutritional programming and the development of hypertension. In Development of the Hypertensive Phenotype: Basic and Clinical Studies. Handbook of Hypertension, vol. 19, pp. 539-574 [R McCarty, DA Blizzard and RL Chevalier, editors]. Amsterdam: Elsevier.

Langley-Evans SC, Gardner DS \& Jackson AA (1996a) Association of disproportionate growth of fetal rats in late gestation with raised systolic blood pressure in later life. Journal of Reproduction and Fertility 106, 307-312.

Langley-Evans SC, Gardner DS \& Jackson AA (1996b) Maternal protein restriction influences the programming of the rat hypothalamic-pituitary-adrenal axis. Journal of Nutrition 126, 1578-1585.

Langley-Evans SC, Phillips GJ \& Jackson AA (1994) In utero exposure to maternal low protein diets induces hypertension in weanling rats, independently of maternal blood pressure changes. Clinical Nutrition 13, 319-324.

Langley-Evans SC, Sherman RC, Welham SJM, Nwagwu MO, Gardner DS \& Jackson AA (1999a) Intrauterine programming of hypertension: the role of the renin-angiotensin system. Biochemical Society Transactions 27, 88-93.

Langley-Evans SC, Welham SJM \& Jackson AA (1999b) Fetal exposure to a maternal low protein diet impairs nephrogenesis and promotes hypertension in the rat. Life Sciences 64, 965-974.
Langley-Evans SC, Welham SJM, Sherman RC \& Jackson AA (1996c) Weanling rats exposed to maternal low protein diets during discrete periods of gestation exhibit differing severity of hypertension. Clinical Science 91, 607-615.

Luke RG (1981) Uremia and the BUN. New England Journal of Medicine 305, 1213-1215.

Mackenzie HS \& Brenner BM (1995) Fewer nephrons at birth: a missing link in the etiology of essential hypertension? American Journal of Kidney Disease 26, 91-98.

Merlet-Benichou C, Gilbert T, Muffat-Joly M, Lelievre-Pegorier M \& Leroy B (1994) Intrauterine growth retardation leads to a permanent nephron deficit in the rat. Pediatric Nephrology $\mathbf{8}$, $175-180$.

Owen WF, Lew NL \& Liu Y (1993) The urea reduction ratio and serum albumin concentration as predictors of mortality in patients undergoing haemodialysis. New England Journal of Medicine 329, 1001-1006.

Ozanne SE, Smith GD, Tikerpae J \& Hales CN (1996) Altered regulation of hepatic glucose output in the male offspring of protein-malnourished rat dams. American Journal of Physiology 270, E559-E564.

Pickard CL, McCarthy HD, Browne RF \& Jackson AA (1996) Altered insulin response to a glucose load in rats following exposure to a low protein diet in utero. Proceedings of the Nutrition Society 55, 44A.

Sherman RC \& Langley-Evans SC (1998) Early administration of angiotensin-converting enzyme inhibitor captopril, prevents the development of hypertension programmed by intrauterine exposure to a maternal low protein diet. Clinical Science 94, 373381.

Smith PK, Krohn RI, Hermanson GT, Mallia AK, Gartner FH, Provenzano MD, Fujimoto EK, Goelke NM, Olson BJ \& Klenk DC (1985) Measurement of protein using bicinchonic acid. Analytical Biochemistry 150, 76-85.

Snoeck A, Remacle C, Reusens B \& Hoet JJ (1990) Effect of a low protein diet during pregnancy on the fetal rat endocrine pancreas. Biology of the Neonate 57, 107-118.

Zeman FJ (1968) Effects of maternal protein restriction on the kidney of the newborn young of rats. Journal of Nutrition 94, $111-117$. 